\title{
IMPLEMENTASI KEBIJAKAN PEMBANGUNAN PERUMAHAN BAGI MASYARAKAT BERPENGHASILAN RENDAH DI RUSUNAWA KELURAHAN DUSUN BESAR KECAMATAN SINGARAN PATI KOTA BENGKULU
}

\author{
Oleh: \\ ANITA MARIANATA \\ Dosen Prodi Administrasi Publik Fakultas Ilmu Sosial UNIVED Bengkulu
}

\begin{abstract}
This study aims to determine the implementation of housing development policy for low income communities in Kelurahan Dusun Besar, Singaranpati Subdistrict, Bengkulu City. This study uses a qualitative desciptive method and the data collection was conducted through in-depth interviews, focus group discussions, and documentation method. The results shows that the implementation of Rusunawa (simple rented flats) policy development in Kelurahan Dusun Besar has not been appropriate with expectation. The physical condition of Rusunawa is not habitable, because the construction of Rusunawa has not finished or neglected until now. From the 96 residence in total, only 23 units were inhabited. The Rusunawa management also did not collect the rent, due the condition of facilities in Rusunawa was not adequate such as unavailable water supply. Besides, the Rusunawa management recognized that there was no authority resignation directly from the government of Bengkulu City to the management, so that the managers did not know exactly when these flats will be resolved or the rent expense will be charged. Moreover, there was no program to improve the economy of low-income communities, so the empowerment of lowincome communities living in Rusunawa was impossible.
\end{abstract}

Keywords: Implementation of Policy, Housing Policy, Socio-Economics, LowIncome Communities

\section{PENDAHULUAN}

Jumlah penduduk yang bertambah mengakibatkan kebutuhan akan tempat tinggal atau rumah juga meningkat. Kekurangan perumahan di Kota Bengkulu mencapai 16.000 unit per 5 tahun sehingga potensi pengembangan kawasan permukiman masih tinggi di daerah Kota Bengkulu. Secara keseluruhan, kekurangan rumah di Provinsi Bengkulu mencapai 52.000 unit per 5 tahun untuk memenuhi kebutuhan hunian masyarakat di Provinsi Bengkulu (Media Indonesia, 2011). Hal ini membuat pemerintah pusat khususnya Kementerian Perumahan memasukkan wilayah Kota Bengkulu ke dalam kebijakan RPJPN (Rencana Jangka Panjang Negara) mengenai pembangunan Rusunawa tahun 
anggaran 2007. Pembangunan Rusunawa ini menjadi tanggung jawab Direktorat Jenderal Cipta Karya, dalam hal ini Ditjen Cipta Karya Kota Bengkulu.

Pemerintah Kota Bengkulu dalam hal ini mengeluarkan kebijakan yang mengatur mengenai Rusunawa yaitu Peraturan Walikota Bengkulu nomor 17 tahun 2012 tentang pengelolaan Rumah Susun Sederhana Sewa (Rusunawa) Kota Bengkulu. Perwal nomor 17 tahun 2012 mengatur mengenai untuk memanfaatkan bangunan Rusunawa yang telah dibangun perlu segera dikelola agar tujuan pembangunan Rusunawa berhasil dan berdaya guna sehingga dapat mencapai pemenuhan rumah tinggal yang terjangkau, bermanfaat, nyaman, aman, dan sehat bagi penghuninya.

Penelitian ini dilatarbelakangi karena pembangunan Rusunawa di Kelurahan Dusun Besar sampai saat ini belum sesuai dengan tujuan pembangunannya dan masih banyaknya permasalahan yang muncul dalam pembangunan Rusunawa tersebut di antaranya rusaknya sarana dan prasarana Rusunawa, serta tidak adanya upaya nyata yang dilakukan pemerintah Kota Bengkulu untuk melakukan perbaikan. Pemerintah Kota Bengkulu dalam hal ini berperan sebagai pihak yang berperan dalam menyediakan dan memberikan kemudahan dan bantuan perumahan dan kawasan permukiman bagi masyarakat melalui penyelenggaraan perumahan dan kawasan permukiman yang berbasis kawasan serta keswadayaan masyarakat sesuai dengan yang disebutkan dalam Undang-Undang Nomor 1 Tahun
2011 Tentang Perumahan dan Kawasan Permukiman.

Pemerintah Kota Bengkulu menetapkan sewa Rusunawa di Kelurahan Dusun Besar, Kecamatan Singaranpati, Kota Bengkulu 30 persen dari Upah Minimum Provinsi yang diatur dalam Peraturan Wali Kota (Perwal) Bengkulu. Rusunawa tersebut difungsikan untuk ditempati masyarakat ekonomi menengah ke bawah, yang akan disewakan sesuai dengan peraturan pemerintah pusat, sedangkan pemerintah daerah menyiapkan peraturan, personil, calon penghuni. Kondisi Rusunawa di Kelurahan Dusun Besar, Kecamatan Singaranpati, Kota Bengkulu cukup memprihatinkan bahkan sebagian rusak berat akibat tidak dimanfaatkan karena pembangunan yang tidak selesai. Berdasarkan pantauan TVRI Bengkulu pada 26 April 2010, dari 96 unit kamar yang ada hanya 10 unit kamar yang telah ditempati. Pembangunan Rusunawa Kelurahan Dusun Besar, Kecamatan Singaranpati, Kota Bengkulu dimulai pada tahun 2007 dengan menghabiskan dana pusat sebesar 9 milyar rupiah. Pembangunan tersebut menghadapi kendala antara lain Rusunawa tersebut tidak layak huni, dan pembagian urusan antara pemerintah pusat dan pemerintah Kota Bengkulu tidak jelas, sehingga pelaksanaan pembangunan menjadi bermasalah.

Kondisi fisik serta sarana dan prasarana rusunawa sudah rusak, serta rusunawa dihuni secara illegal oleh masyarakat tunawisma. Hal ini menunjukkan adanya ketidaktepatan sasaran penghuni rumah susun sesuai dengan Permenpera Nomor 14 Tahun 
2007 tentang pengelolaan rumah susun sewa sederhana dan Ketentuan Badan Pengelola Rusunawa Kelurahan Dusun Besar, Kecamatan Singgaranpati, Kota Bengkulu, sehingga program pembangunan rumah susun ini kurang memberikan kontribusi bagi pemecahan permasalahan perumahan. Syarat penghuni Rusunawa yaitu, memiliki penghasilan di bawah UMP (Upah Minimum Provinsi), maksimal memiliki 3 orang anak, penduduk asli kota Bengkulu, dan belum memiliki rumah. Permasalahan yang diangkat dalam tesis ini adalah seperti apa implementasi kebijakan di Kota Bengkulu, khususnya pembangunan perumahan bagi masyarakat berpenghasilan rendah di Rusunawa Kelurahan Dusun Besar, Kecamatan Singaranpati, Kota Bengkulu. Pembangunan perumahan diharapkan dapat memberikan kontribusi langsung terhadap peningkatan kesejahteraan dan pengentasan kemiskinan. Tujuan penelitian ini adalah untuk menggambarkan implementasi kebijakan pembangunan perumahan bagi masyarakat berpenghasilan rendah di Rusunawa Kelurahan Dusun Besar, Kecamatan Singaranpati, Kota Bengkulu.

\section{METODE PENELITIAN}

Jenis penelitian yang
digunakan adalah penelitian
deskriptif. Menurut Whitney dalam
Nazir (2003:41), Jenis penelitian
deskriptif adalah pencarian fakta
dengan interpretasi yang tepat.
Penelitian yang dilakukan peneliti
digolongkan sebagai penelitian
deskriptif karena penelitian ini
berusaha memaparkan bagaimana

implementasi program perumahan perkotaan dalam program pembangunan Rusunawa Kelurahan Dusun Besar.

Berdasarkan manfaatnya, penelitian ini termasuk penelitian murni, karena penelitian ini dilakukan karena kebutuhan peneliti sendiri dalam kerangka akademis. Penelitian murni biasanya dilakukan dalam kerangka pengembangan ilmu pengetahuan dan penelitian murni lebih banyak ditujukan bagi pemenuhan keinginan dan kebutuhan peneliti, umumnya peneliti memiliki kebebasan untuk menentukan permasalahan apa yang akan diteliti. Fokus penelitian ada pada logika dan rancangan penelitian yang dibuat oleh peneliti sendiri (Prasetyo dan Jannah, 2005:67).

Penelitian ini merupakan penelitian crossectional, karena penelitian ini hanya dilakukan dalam satu waktu. Penelitian ini hanya digunakan dalam waktu yang tertentu, dan tidak akan dilakukan penelitian lain di waktu yang berbeda untuk diperbandingkan. Adapun metode yang digunakan dalam penelitian ini adalah data didapat melalui data sekunder diperoleh melalui studi kepustakaan yang dilakukan dengan mengumpulkan literatur atau buku yang berhubungan dengan penelitian, serta dokumendokumen lainnya. Untuk mendukung studi lapangan peneliti melakukan wawancara mendalam dengan narasumber yang kompeten di bidangnya masing-masing

Penelitian ini menggunakan analisis data kualitatif dalam menggunakan data yang diperoleh. Data yang diperoleh dari hasil wawancara, catatan lapangan, dan 
dokumentasi yang diperoleh untuk kemudian disusun secara sistematis serta ditentukan mana yang terlebih dahulu akan dipelajari dan membuat kesimpulan sehingga dapat dipahami oleh semua pihak.

\section{HASIL PENELITIAN DAN PEMBAHASAN}

Penelitian dilakukan dengan menggunakan metode focus group discussion (FGD), agar hasil penelitian yang dilakukan mendapatkan jawaban yang jujur dan terdapat perdebatan dari diskusi yang dilakukan pada saat penelitian. Metode FGD lebih memudahkan peneliti dalam menggabungkan jawaban-jawaban para informan, dan hanya dilakukan satu waktu saja. Berikut hasil penelitian yang dilakukan, yaitu:

\section{Kerjasama Stakeholder Dalam Pengadaan dan Perizinan Rusunawa Dusun Besar}

Dari hasil penelitian diketahui bahwa dalam pengadaan dan perizinan rusunawa Dusun Besar tidak terdapat kerja sama yang baik. Saling lempar tanggung jawab dan kewajiban masing-masing instansi yang terkait dalam pembangunan dan pengelolaan rusunawa Dusun Besar. Tidak adanya penyerahan kewenangan secara langsung dari pemerintah pusat dijadikan alasan utama oleh pemerintah Kota Bengkulu dan stakeholder untuk tidak melanjutkan pembangunan dan membiarkan bangunan rusunawa tersebut terbengkalai.

\section{Pembiayaan Rusunawa Dusun Besar}

Dari hasil penelitian diketahui bahwa tidak adanya tindakan pemerintah Kota Bengkulu untuk mengelola dan menggurus rusunawa Dusun Besar, membuat pihak Kecamatan Singaranpati mengambil tindakan sendiri untuk mengelola dan mengurus rusunawa tersebut. Sifat sosial pihak Kecamatan Singaranpati dengan menggratiskan biaya sewa rusunawa merupakan salah satu tindakan yang mereka lakukan sendiri. Alasan mereka agar rusunawa tersebut juga bisa dimanfaatkan, walaupun seadanya dengan keterbatasan sarana dan prasarana.

\section{Organisasi Pengelolaan Rusunawa Dusun Besar}

Dari hasil penelitian diketahui bahwa pemerintah Kota Bengkulu tidak tanggap dan tidak ada tindakan dalam pemberdayaan ekonomi bagi penghuni rusunawa. Sehingga tidak ada peningkatan perekonomian bagi penghuni rusunawa. Pengelola tidak dapat melakukan pemberdayaan ekonomi dikarenakan tidak memiliki dana untuk melakukan pemberdayaan ekonomi bagi penghuni rusunawa.

\section{Penetapan Peraturan Bagi Penghuni Rusunawa Dusun Besar Dari hasil penelitian} diketahui bahwa untuk bisa menjadi penghuni rusunawa harus melewati proses seleksi dan wawancara yang dilakukan oleh pengelola rusunawa Dusun Besar. Calon penghuni yang kemudian ditetapkan menjadi penghuni memiliki hak dan kewajiban sesuai yang tercantum di 
dalam Perwal no.17 tahun 2012. Penghuni rusunawa Dusun Besar hingga saat ini tidak dikenakan biaya sewa sama sekali, sehingga sangat membantu penghuni dalam perekonomian. Tetapi, hal tersebut tidak boleh berlangsung berkepanjangan karena yang menjadi tujuan rusunawa dibangun ialah menjadikan rusunawa tersebut sebagai aset daerah dalam perumahan. Untuk itu penyelesaian pembangunan rusunawa Dusun Besar seharusnya segera diselesaikan, agar rusunawa tersebut dapat berfungsi sesuai dengan tujuan pembangunannya.

\section{IMPLEMENTASI KEBIJAKAN PEMBANGUNAN PERUMAHAN RUSUNAWA DUSUN BESAR, KOTA BENGKULU}

Tujuan dari pembangunan Rusunawa yang dilihat berdasarkan UU nomor 16 tahun 1985 tentang rumah susun dan peraturan walikota nomor 17 tahun 2012 tentang pengelolaan rusunawa. Terdapat empat aspek yang menjadi pokok pembahasan pada penelitian yaitu: kerjasama dengan berbagai stakeholder dalam pengadaan dan perizinan Rusunawa Dusun Besar, pembiayaan rusunawa Dusun Besar, organisasi pengelolaan Rusunawa Dusun Besar, dan penetapan peraturan bagi penghuni. Kemudian dari keempat aspek tersebut dapat mencapai tujuan dari pembangunan Rusunawa Dusun Besar.

\section{Kerjasama dengan Berbagai Stakeholder dalam Pengadaan dan Perizinan Rusunawa Kelurahan Dusun Besar}

Pengembangan perumahan sesungguhnya diprogramkan sebagai tanggung jawab masyarakat bersama dengan stakeholder lainnya. Sebagai hak dasar yang fundamental dan sekaligus menjadi prasyarat bagi setiap orang untuk bertahan hidup dan menikmati kehidupan yang bermartabat, damai, aman dan nyaman maka penyediaan perumahan dan permukiman yang memenuhi prinsip-prinsip layak dan terjangkau bagi semua orang.

Oleh karena itu, dibangunlah Rusunawa Kelurahan Dusun Besar ini pada tahun 2007 dalam Kawasan Kelurahan Dusun Besar, Kecamatan Singaranpati. Untuk membangun Rusunawa Kelurahan Dusun Besar ini, Kementerian Perumahan Rakyat menugaskan Ditjen Cipta Karya untuk membangun di Kelurahan Dusun Besar karena lahan yang tersedia memang merupakan milik resmi yang berstatus Hak Milik, Hak Guna Bangunan, Hak Pakai atas Tanah Negara atau Hak Pengelolaan (pasal 7 No. 16/1985). Dalam pembangunan ini juga dilakukan kemitraan dengan berbagai instansi. Dalam hal ini, keterlibatan Pemerintah Pusat adalah sebagai pemberian dana untuk fisik bangunan rusunawa. Sedangkan keterlibatan Pemerintah Kota Bengkulu ialah dalam proses perizinan bangunan dan Ditjen Cipta Karya PU Kota Bengkulu sendiri bertindak sebagai perencana, pembangunan fisik rusunawa dan sekaligus sebagai pengelola.

Terbukti dengan program pembangunan Rusunawa Dusun Besar yang menelan biaya sebesar Rp. 9 Milyar tidak selesai, dan 
fasilitas Rusunawa masih jauh dari kata layak.

Hal ini menunjukkan bahwa telah terjadi penyimpangan anggaran pembangunan Rusunawa Dusun Besar. Jika dana Rp. 9 Milyar digunakan sesuai peruntukannya, maka Rusunawa Dusun Besar akan selesai pembangunannya dan tidak terbengkalai. Menurut salah satu informan yang jati dirinya peneliti tidak menyebutkan, mengakatan bahwa pada saat persetujuan pemberian izin pembangunan Rusunawa Dusun Besar terdapat penggelembungan anggaran oleh pihak pemerintah Kota Bengkulu sendiri dan juga oknum Ditjen Cipta Karya Bengkulu. Penggelembungan anggaran seperti harga bahan bangunan, harga ganti rugi terhadap warga yang tanahnya terpakai untuk pembangunan. Ke semua itu harus sesuai dengan permintaan pemerintah Kota Bengkulu, kemudian baru diberikan perizinan untuk pembangunan Rusunawa Dusun Besar.

\section{Pembiayaan Rusunawa Kelurahan Dusun Besar}

Biaya

konstruksi

pembangunan rumah susun sederhana memerlukan biaya yang cukup tinggi. Dalam pembangunan rusunawa Dusun Besar ini, seluruh modal yang disertakan merupakan Penyertaan Modal Negara (PMN) sebesar 9 Milyar Rupiah. Pembelian tanah, pendanaan bangunan, biaya perbaikan bangunan dan lingkungan dengan skala kerusakan besar, biaya pengadaan sarana dan prasarana lingkungan dibebankan kepada negara berdasarkan persetujuan Kementerian Keuangan.

\section{Organisasi Pengelolaan Rusunawa Dusun Besar}

Di Rusunawa Kelurahan Dusun Besar ini yang menjadi pengelola ialah Kantor Kecamatan Singgaranpati itu sendiri. Pada tahun 2012, dibentuklah suatu unit pengelola yang menangani seluruh rusunawa yang dibangun dan dikelola oleh Kecamatan Singgaranpati. Adapun pembentukan unit pengelola sebagaimana yang disebutkan dalam Perwal No.17 Tahun 2012 Pasal 30.

\section{Penetapan Peraturan Bagi Penghuni}

Pengelolaan rumah susun pada dasarnya dimulai dari seleksi calon penghuni. Pada dasarnya, persyaratan untuk dapat menempati rumah susun sederhana sewa ini tidaklah rumit, seluruh warga Indonesia berhak untuk menempati rumah susun ini tentunya dengan kriteria-kriteria yang telah ditentukan, yakni masyarakat berpenghasilan rendah dengan mengajukan KTP (Kartu Tanda Penduduk), KK (Kartu Keluarga), surat nikah.

\section{HAMBATAN IMPLEMENTASI KEBIJAKAN PEMBANGUNAN RUSUNAWA DUSUN BESAR}

a. Kerjasama dengan Berbagai Stakeholder dalam Pengadaan dan Perizinan Rusunawa Kelurahan Dusun Besar

Dalam mengimplementasikan suatu kebijakan dalam bentuk program seperti Rusunawa Kelurahan Dusun Besar ini, diperlukan kerjasama yang baik antara stakeholder yang terlibat dalam pembangunan Rusunawa 
Dusun Besar. Pembangunan Rusunawa Dusun Besar melibatkan pemerintah pusat dalam hal ini diwakili oleh Ditjen Cipta Karya Kota Bengkulu dan pemerintah daerah Kota Bengkulu.

\section{b. Pembiayaan Rusunawa Dusun Besar}

Pembangunan Rusunawa

Dusun Besar yang tidak selesai, merupakan bentuk dari kekurangan pembiayaan. Padahal anggaran yang diberikan oleh pemerintah pusat merupakan anggaran untuk pembangunan Rusunawa hingga selesai. Tetapi banyak terjadi penyimpangan pada anggaran pembangunan yang terjadi, sehingga pembangunan Rusunawa Dusun Besar tidak sesuai dengan perencanaan.

\section{c. Organisasi Dalam Pengelolaan Rusunawa Dusun Besar}

Permasalahan yang dihadapi oleh pihak pengelola terkait keberlangsungan dalam melakukan pengelolaan ialah kurangnya dukungan dana dari pemerintah kepada pengelola. Rusunawa Kelurahan Dusun Besar ini sebagai contoh kasus rumah susun yang memiliki sumber dana dari pusat, yang dianggap sebagai salah satu contoh yang kurang dapat memelihara kondisi fisik bangunannya. Hal ini salah satunya diakibatkan oleh tidak jelasnya penyelesaian pembangunan Rusunawa.

\section{d. Penetapan Peraturan Bagi Penghuni}

Lemahnya keberdayaan ekonomi dan kurangnya waktu yang umumnya menjadi ciri yang melekat pada masyarakat berpenghasilan rendah, karena sebagian waktu harian umumnya tidak digunakan untuk memelihara atau melakukan kegiatan yang berhubungan dengan penjagaan kualitas lingkungan permukiman, tetapi lebih digunakan untuk bekerja demi penghasilan yang lebih tinggi. Kegiatan harian ibu rumah tangga umumnya digunakan untuk menjaga dan mengasuh anak, atau untuk membantu suami berdagang atau melakukan usaha lainnya.

\section{PENUTUP}

\section{Kesimpulan}

Pembangunan rumah susun sederhana sewa merupakan suatu program pemerintah untuk penataan ruang terbuka hijau dan efisiensi lahan. Kebijakan pembangunan Rusunawa Dusun Besar juga terkait dengan adanya tuntutan kebutuhan perumahan yang layak bagi penduduk Kota Bengkulu terutama bagi mereka yang memiliki penghasilan rendah. Implementasi kebijakan pembangunan perumahan bagi masyarakat berpenghasilan rendah di Rusunawa Dusun Besar ini belum dilaksanakan dengan yang diharapkan, dikarenakan pada kenyataannya di lapangan masih ditemukan beberapa hambatan yang berpotensi menimbulkan adanya permasalahan yang semakin rumit.

\section{Saran}

Berikut ini terdapat beberapa saran sebagai bahan masukan guna mengatasi permasalahan yang terjadi, yaitu:

a. Kerjasama dengan berbagai stakeholder dalam pengadaan Rusunawa Kelurahan Dusun Besar: kerjasama yang 
dilakukan harus berjalan optimal.

b. Pembiayaan Rusunawa Dusun Besar: pembiayaan pembangunan Rusunawa seharusnya digunakan sesuai dengan kapasitas pengunaannya.

c. Organisasi pengelolaan Rusunawa Dusun Besar: kurangnya dukungan dana bagi pengelola untuk melaksanakan tugas pengelolaan Rusunawa Dusun Besar, harus ditindaklanjuti.

d. Penetapan peraturan bagi penghuni: penghuni harus merupakan orang-orang yang berpenghasilan rendah, dan harus ada pemberdayaan ekonomi oleh Pemerintah Kota Bengkulu sebagai bentuk peningkatan ekonomi.

\section{DAFTAR PUSTAKA}

Abidin, Said Zainal. 2006. Kebijakan Publik (Cetakan Ketiga). Jakarta, Suara Bebas

Al Rashid, Harun. 1985. Upaya Penyelesaian Sengketa Sewa Menyewa Perumahan Menurut Ketentuan Perundangundangan. Jakarta, Ghalia Indonesia

Dwidjowijoto, Riant Nugroho. 2003. Kebijakan Publik : Formulasi, Implementasi dan Evaluasi. Jakarta, PT Elex Media Komputindo
Dunn, William N. 2000. Pengantar Analisis Kebijakan Publik, Edisi Kedua. Yogyakarta, Gadjah Mada University Press

Hauser, Philip M, dkk. 1985. Penduduk dan Masa Depan Perkotaan. Jakarta, Yayasan Obor Indonesia

Huque, Ashraf. 1975. The Myth of Self Help Housing. Washington D.C, Oxford University Press

Islamy, Irfan. 1992. Prinsip-prinsip Perumusan Kebijaksanaan Negara. Jakarta, Bumi Aksara

Komarudin. 1997. Menelusuri Pembangunan Perumahan dan Permukiman. Jakarta, Yayasan Realestat Indonesia

Mustopadidjaja, AR \& Bintoro, Tjokroamodjojo. 1999.

Administrasi Negara,

Demokrasi dan Masyarakat Madani. Jakarta, LAN

Nazir, Moh. 2003. Metode Penelitian. Jakarta, Penerbit Ghalia Indonesia.

Neuman, W. Lawrence. 2006. Social Research Methodes: Qualitative and Quantitative Approaches.

Panudju, Bambang. 1999. Pengadaan Perumahan Kota Dengan Peran Serta Masyarakat Berpenghasilan Rendah. Bandung, Penerbit Alumni. 
Parsons, Wayne. 2008. Public Policy : Pengantar Teori dan Praktik Analisis Kebijakan (Edisi 1, cetakan ke-3). Jakarta, Kencana

Prasetyo, Bambang dan Lina Miftahul Jannah. 2005. Metode Penelitian Kuantitatif: Teori dan Aplikasi. Jakarta, PT Rajagrafindo Persada

Sugiyono. 2007. Memahami Penelitian Kualitatif. Bandung, Alfabeta

Todaro, Michael P. dan Steven C. Smith. 2006. Pembangunan Ekonomi. Jakarta, Erlangga

Usman, Husain dan Purnomo Setiady Akbar. 2006. Metodelogi Penelitian Sosial. Jakarta, Bumi Aksara

Wahab, Solichin Abdul. 1990. Pengantar Analisis Kebijaksanaan Negara. Jakarta, PT Rineka Cipta

Wahab, Solichin Abdul. 1991. Analisis Kebijakan dari Formulasi ke Implementasi Kebijaksanaan Negara. Jakarta, Bumi Aksara

Winarno, Budi. 2002. Teori dan Proses Kebijakan Publik. Yogyakarta, Media Pressindo

Bappenas. Percepatan Pembangunan Infrastruktur. www.bappenas.go.id. Diunduh pada tanggal 10 Februari 2013
Bappenas. Pembangunan Perdesaan. www.bappenas.go.id. Diunduh pada tanggal 10 Februari 2013

Buku Pintar Rusunawa. www.infopublik.com. Diunduh pada tanggal 25 Januari 2013

Direktorat Jenderal Cipta Karya. Pemerintah Targetkan Kawasan Kumuh Perkotaan Hilang Pada 2020. www.ciptakarya.pu.go.id. Diunduh pada tanggal 25 Juli 2012

Direktorat Jenderal Cipta Karya. Hunian Vertikal adalah Salah Satu Solusi. Tidak diterbitkan

Indonesia, Statistik. Pembangunan Perumahan dan Permukiman Perkotaan dan Perdesaan. www.datastatistik-indonesia.com. Diunduh pada tanggal 09 Februari 2013

Kementerian Perumahan Rakyat. 2009. Laporan akhir Model Penyelenggaraan Rusuna Sewa Bagi Masyarakat Menengah Bawah oleh Badan Usaha. Tidak Diterbitkan

Kurniasih, Sri. Usaha Perbaikan Permukiman Kumuh Di Petukangan Utara-Jakarta Selatan. www.peneliti.bl.ac.id. Diunduh pada tanggal 01 Agustus 2012

Peraturan Menteri Perumahan Rakyat Nomor 14 Tahun 2007 Tentang Pengelolaan Rumah Susun Sewa Sederhana

Peraturan Walikota Bengkulu Nomor 17 Tahun 2012 Tentang Pengelolaan Rusunawa Kota Bengkulu 
Renstra dan Kebijakan. Rencana Strategis dan Kebijakan Pembangunan Perumahan 2005$2009 . \quad$ www.kemenpera.go.id. Diunduh pada tanggal 17 Desember 2012

Tjiptoherijanto, Prijono. Urbanisasi Mobilitas dan Perkembangan Perkotaan di Indonesia. Tanggal 05 Oktober 2007. robbyalexandersirait.wordpress.com. Diunduh pada tanggal 09 Februari 2013
Perum Perumnas. Produk Rusunawa. www.perumnas.co.id. Diunduh pada tanggal 20 Februari 2010

Asy"ari, Mohammad Yusuf. Lima Tahun Perumahan Rakyat (20052009). www.setneg.go.id. Tanggal 31 Agustus 2009. Diunduh pada tanggal 30 Desember 2012 